\title{
Underbalanced drilling technology with air injection connector
}

\author{
Jiansheng Jiang $\cdot$ Fazle Rabbi $\cdot$ Qingsheng Wang
}

Received: 29 January 2013/Accepted: 4 November 2013/Published online: 19 November 2013

(c) The Author(s) 2013. This article is published with open access at Springerlink.com

\begin{abstract}
Underbalanced drilling technology has been extended deeply into every corner of the industrial productions and processes. In particular, the technology has a wide range of applications in oil and gas industries for the product design, manufacturing and construction process. In this work, a new air injection connector system has been developed for underbalanced drilling. The system development includes five key issues: original design, manufacturing control, experimental method, on-spot drilling design, and field work point control. The air injection connector system plays an important role and can significantly reduce potential losses during the drilling process.
\end{abstract}

Keywords Underbalanced drilling - Air injection connector · Process control · Horizontal well · On-site procedure

\section{Introduction}

The underbalanced drilling technology has been regarded as a good drilling technology for years (Omland et al.

\footnotetext{
J. Jiang

Department of Mechanical Engineering, China University of Petroleum, 102249 Beijing, China

J. Jiang $\cdot$ F. Rabbi $\cdot$ Q. Wang $(\bowtie)$

Department of Fire Protection and Safety, Boots \& Coots Center for Fire Safety and Pressure Control, Oklahoma State University, Stillwater, OK 74078, USA

e-mail: qingsheng.wang@okstate.edu

F. Rabbi - Q. Wang

School of Chemical Engineering, Oklahoma State University, Stillwater, OK 74078, USA
}

2007). Major advancements have been made in the past decades to determine the effects of adding particles to drilling fluids (Luo et al. 2000). According to the report of some oil companies, by using the underbalanced drilling technology, horizontal well production increased ten times compared with the conventional drilling technology (Liu and Meng 2005). Nowadays, inflatable drilling fluid has been widely used in the underbalanced drilling, either through the riser or through the downhole air injection, which usually works with compressed air from compressor or booster (Rolf et al. 2001).

Downhole air injection technology involves parasitic pipe, concentric pipe, drill string, and coiled tubing drilling. In each method, compressed air, natural gas or nitrogen is injected into the downhole drilling fluid. The key technologies of underbalanced drilling are generating and maintaining underbalanced conditions, well control technology, ground processing of the produced fluids and electromagnetic measure while drilling (MWD) technology (Liu and Meng 2005). In recent years, the progress of underbalanced drilling technology is mainly focused on well control, drilling fluids, program design, and other special tools (Rommetveit et al. 2005; Li and Yan 2005; Chen et al. 2010; Zhang et al. 2009; Liu and Meng 2005; Zhou et al. 2003).

In this work, a new underbalanced drilling tool called air injection connector system with independent intellectual property rights has been developed. The newly developed underbalanced drilling tool has been applied to the field work on horizontal well underbalanced drilling services. In the on-site procedure, the air injection connector system was put down into the well to realize the underbalanced drilling. Details of the technology have been illustrated in this work, which plays an important role in the on-site procedure engineering design. 
Fig. 1 Mechanical structure of the air injection connector system ( 1 drilling mud, 2 air injection connector, 3 highpressure hose, 4 casing connector, 5 casing coupling)
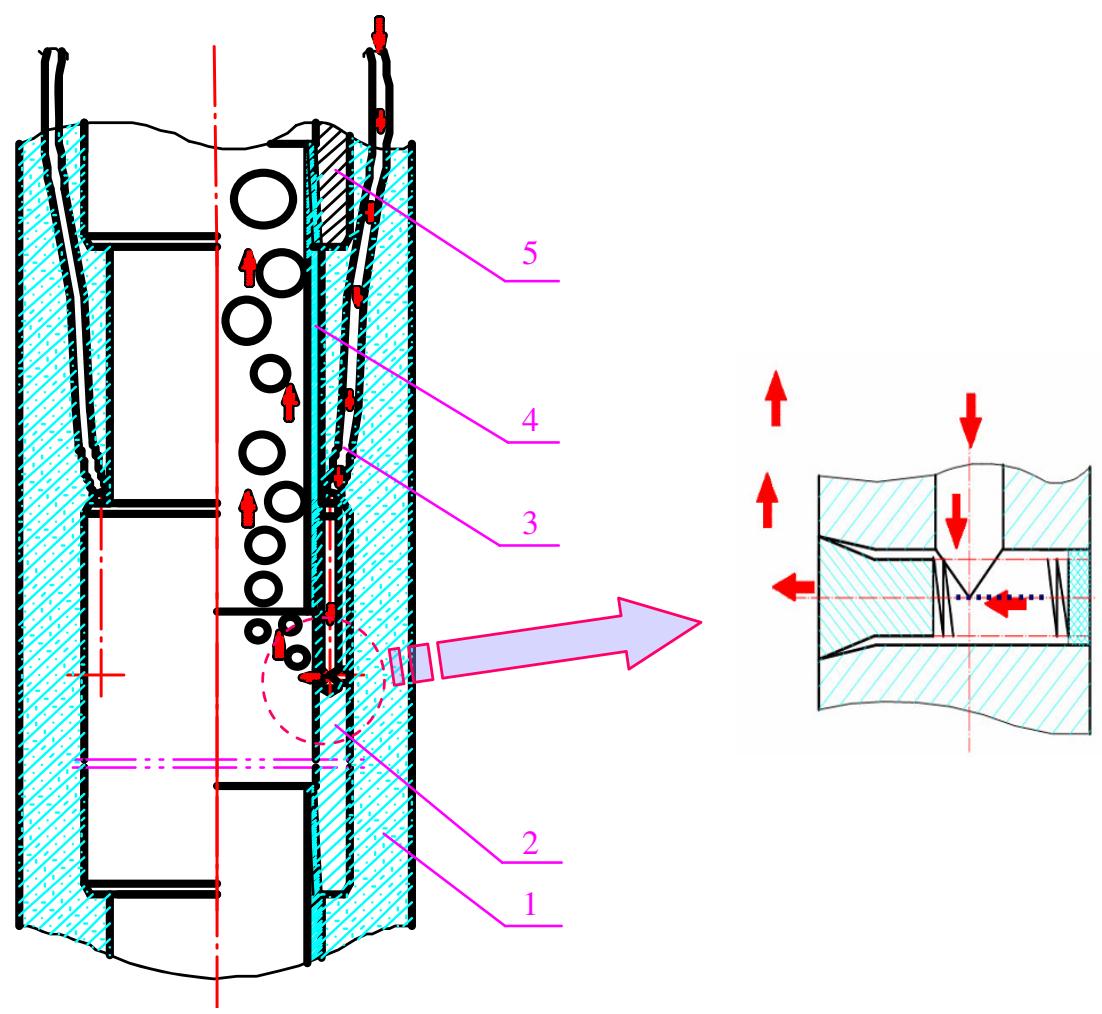

\section{The design of air injection connector system}

The air injection connector system is also known as parasitic pipe joints. In the past, underbalanced drilling was usually realized by the principle of the "U-tube", which means another injection well must be made first to form a "U-tube" with the production well to inject high-pressure air when the production well is being drilled. In order to reduce the budget of drilling and to eliminate hazards with few engineering work, the injection well was replaced by the air injection connector system, which is connected on the production casing at a predetermined position down into the bottom of the well with the casing. It will then open a valve to inject air into the casing ring space during drilling to realize underbalanced drilling (Xian et al. 2009). In order to meet the technical requirements of the above process, the air injection connector system must consist of a non-return valve to eliminate backflow. It must be sent downhole together with the casing and be cemented disposable with the casing. After completion of the first phase of drilling process, the air injection connector could be used to inject high-pressure air in the next phase of drilling process. The pressurized air mixed with the drilling mud would help to increase the performance of underbalanced drilling (Fried et al. 1996; Bennion et al. 1998; Misselbrook et al. 1991; Oyatomari et al. 2002).

The design work of air injection connector system mainly includes the mechanical design of air injection

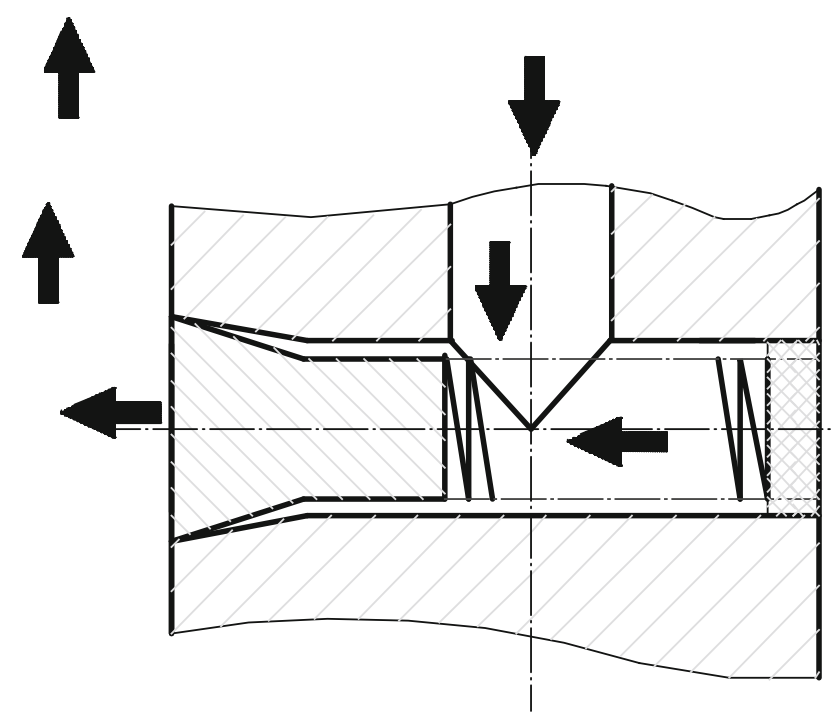

Fig. 2 Structure of the one-way valve

connector, calculations to determine diameter of highpressure hose, and hose laying program design. After calculation of the parameters, the main mechanical structure which is shown in Fig. 1 is determined. The design and calculation of the air connector includes the air pipeline diameter determination, special one-way air inlet valve port, connecting part of the air injection. The spool portion of the poppet valve structure is the key part of the check valve. The other key technology is the strength of the air 


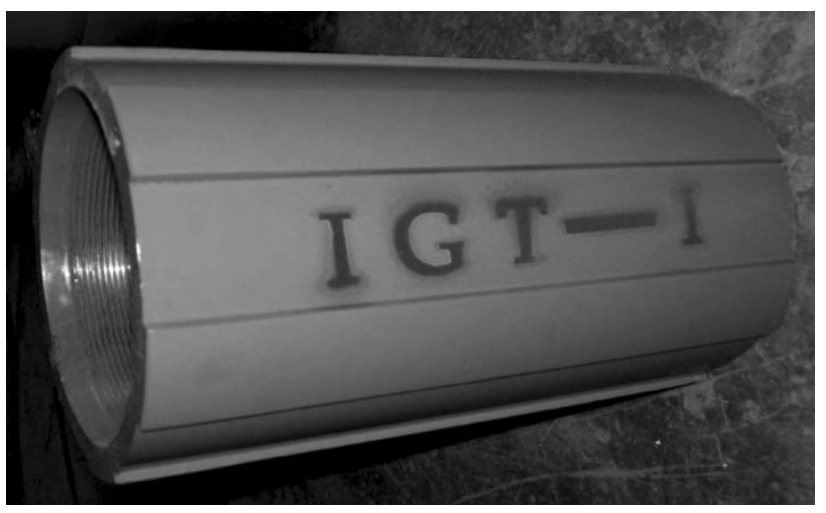

Fig. 3 The unique structure of the air injection connector

pipeline, which should be subject to the greatest pressure. Maximum working pressure of the hydraulic hose was set at $70 \mathrm{MPa}$.

More attention should be paid to hazard elimination during the tool design work, as the tool is the heart of the air injection connector system. The structure of the poppet valve spool section is especially important for the one-way valve. The line between the spool and the valve body (casing wall) ensures the sealing effect of the one-way valve. The left side of spool close to the casing wall ensures that cementing mud does not bond with the inside surface of the valve body. These ensure the safety and reliability of the reverse air injection use. This is the most critical control point. The air injection connector system will fail if the one-way valve does not work. The structure of the one-way valve is shown in Fig. 2.

\section{Manufacturing of the air injection connector}

The quality control on the connector manufacturing becomes more important after completion of the design of the air injection connector. Firstly, the preparation of the designed product was adopted. The strength of the material was emphasized in the procedure of the manufacturing and the mechanical process was also considered for the quality of the tool. In addition to the specially designed one-way valve, a standard one-way valve was fitted in the air injection pipeline joints, which formed three secured barriers together with the one-way valve on the ground air compressor, which ensures the safety and reliability of the underbalanced drilling.

The special one-way valve was commissioned by a professional plant, which used a small batch trial processing. Several technical improvements were made to form the independent processing of the one-way valve's mechanism components. Eventually the unique structure was formed with the monomer cone valve integrally embedded into the check valve assembly, as shown in Fig. 3.

\section{Indoor experiment}

Pipeline joints were tested for probable leaks after completion of processing of the air injector connecting system. The connected one-way valve should be leak-free along with the spool piece during the pressure test. This is an important part of the test for system safety issues. Generally, two dedicated casing male connectors are plugged into the sealed air injection connectors at both ends, which are then injected into the water with hydrostatic pressure for test trials. The underground pressure may reach as high as $20 \mathrm{MPa}$. Pressure test ensures the tightness of the special one-way valve and reverse the operational reliability of the air injection connector. The test will make sure there is no leak and thus prevents future losses during drilling. Pressure test is the most important step of process and loss control during the manufacturing of the tools.

The structure of the air injection connector used in indoor experiment is shown in Fig. 4. Several quality control points were considered during the indoor experiment. First, a fitting pressure test procedure was carried out by injecting water into the connector and gradually suppressing water with the pressure rising to $1 \mathrm{MPa}$ without leakage. After that the pressure of water was gradually increased to 5, 10 and $20 \mathrm{MPa}$, each time holding the pressure for $5 \mathrm{~min}$. The system was relieved from pressure when the joint portion test was completed without any water leakage. Finally, the pressure test connector was removed and the water was poured out of the connector system. The indoor experimental setup is shown in Fig. 5.

\section{The underbalanced drilling project design}

Principle of air injection connector for underbalanced drilling is similar to the principle of the "U-tube". The high-pressure air passes through the ground high-pressure air trachea, injection pipeline and air injection connector into the annulus between the drill string and casing. The air is mixed with the annulus drilling fluids and comes back to the ground. Air injection into drilling mud decreases its density. Thus, underbalanced drilling pressure is reduced, and hence helps to achieve the requirement of the well in coal seam. This working principle is shown in Fig. 6.

The key technology of the engineering project design is the processing principle design and optimization design for drilling parameters. Underbalanced drilling parameter design mainly includes the choice of basic parameters, drawing curve of the air injection pressure value of underbalanced pressure of bottom hole and annulus air injection, drilling fluid displacement, etc. (Hu et al. 2010). Figure 7 shows the test well in different air injection pressure conditions. The bottom hole underbalanced value 
Fig. 4 Assembled structure of the air injection connector

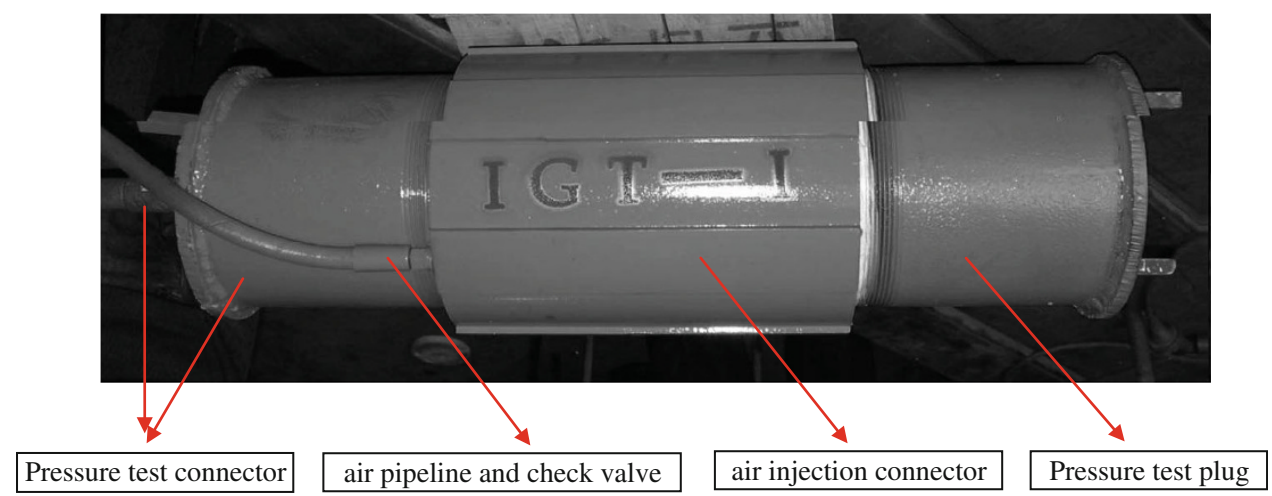

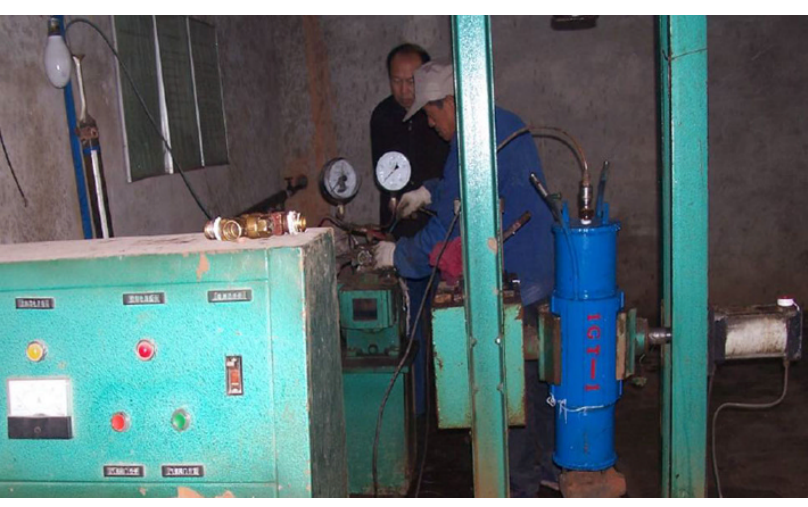

Fig. 5 Hydro test of the pipe joints with the air injection connector

curve changes with the annulus air injection and the drilling fluid displacement.

When the injection pressure is constant, the bottom hole pressure value increases with downhole drilling fluid flow rates monotonically. And the larger the annulus gas injection rate changes, the larger for absolute value of bottom pressure value will be, the better it will be for the underbalanced effect. In the same annulus gas injection rate, the greater the drilling fluid flow rate changes, the smaller the absolute value of bottom hole pressure will be, the underbalanced pressure value will be lower. Under different injection pressure conditions, the underbalanced effect is quite different at the bottom of well. When the annulus gas injection rate $Q_{\mathrm{g}}$ is constant in a given calculation conditions, the higher injection pressure is, which is more closer to the coal reservoir pressure, the gas injection effect will be better, when it can achieve a lower underbalanced drilling pressure value more easily in the reservoir.

Combined by the curves and field engineering requirements for underbalanced drilling, air injection pressure in the range of 3.2-3.5 MPa can lead to a well bottom hole formation due to a better balance. The optimum annulus air injection pressure is stable at 3.5 MPa. Curve for the bottom hole pressure in different amounts of gas injected and liquid flow rates under injecting air pressure with $3.5 \mathrm{MPa}$ has been shown in Table 1 .

\section{On-site procedure and field work operation}

After the successful trial tests of the air injection connectors and auxiliary tools, the on-site procedure was
Fig. 6 Underbalanced drilling with air injection connector
Ground high-pressure air trachea

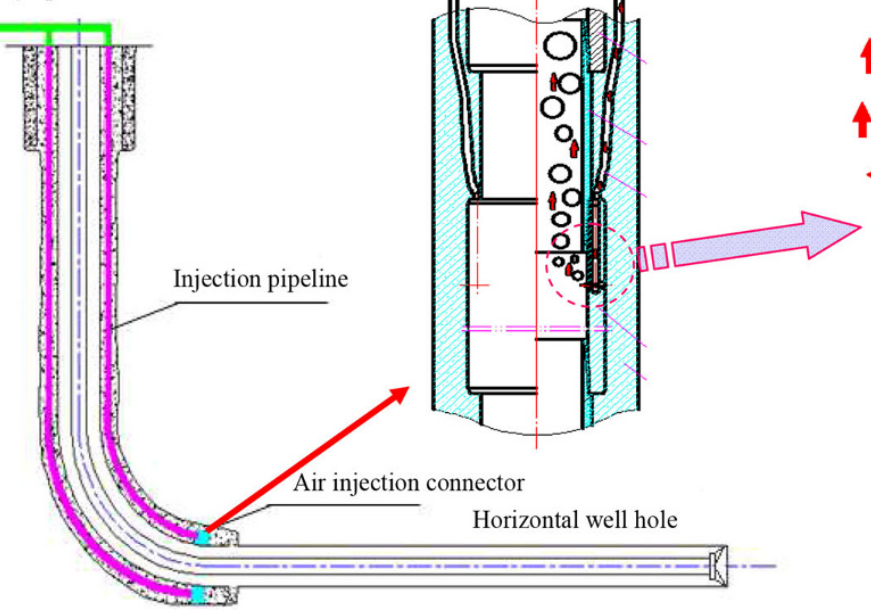

High pressure air

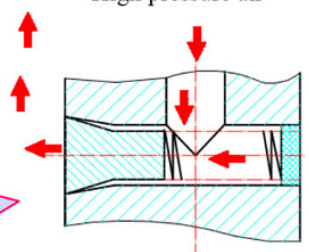




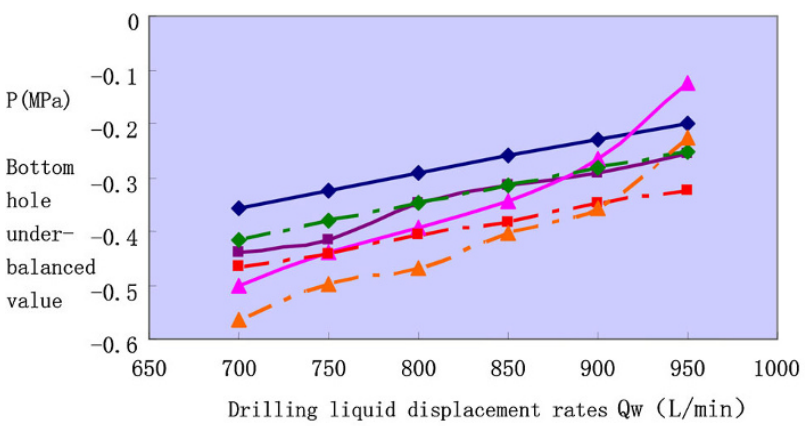

$\begin{array}{ll}\longrightarrow \text { Pin }=3.5 \mathrm{MPa} ; \mathrm{Qg}=22 \mathrm{~m}^{3} / \mathrm{min} & \longrightarrow-\mathrm{Pin}=3.2 \mathrm{MPa} ; \mathrm{Qg}=22 \mathrm{~m}^{3} / \mathrm{min} \\ \longrightarrow \mathrm{Pin}=3.0 \mathrm{MPa} ; \mathrm{Qg}=22 \mathrm{~m}^{3} / \mathrm{min} & \longrightarrow-\mathrm{Pin}=3.5 \mathrm{MPa} ; \mathrm{Qg}=25 \mathrm{~m}^{3} / \mathrm{min} \\ -\mathrm{Pin}=3.2 \mathrm{MPa} ; \mathrm{Qg}=25 \mathrm{~m}^{3} / \mathrm{min} & \longrightarrow-\mathrm{Pin}=3.0 \mathrm{MPa} ; \mathrm{Qg}=25 \mathrm{~m}^{3} / \mathrm{min}\end{array}$

Fig. 7 Bottom hole underbalanced value curve changing with the annulus air injection and drilling fluid displacement under different air injection pressure

conducted on the coalbed methane drilling site in Qinshui County, Shanxi Province, China. Some preparation for the on-site works is required prior to the operation. For example, a $95 / 8$ casing dedicated circular iron plate was machined, on which a hole was set each aside for air injection pipeline penetrating down into the bottom of the well. Some on-site auxiliary tools must be present in advance to ensure the procedure in time. For example, the ground air injection pipeline joints must be $27 / 8$ "standard tubing connectors and the flow valve must be installed on the booster's outlet. The prepared actual length of the air pipeline should be longer than the estimated length approximately by $100 \mathrm{~m}$. Before air injection connectors going down, sufficient number of stainless steel clamps and vices were used to fix the air pipeline around the casings. A special cart should also be prepared to insert the air pipeline at the same time as that of the casing.

Workers should be trained on the on-site procedure and field work operation. The workers should properly know about the new tools and understand the main task of putting down the air injection connector system in the proper position under the well with the casings. Furthermore, all

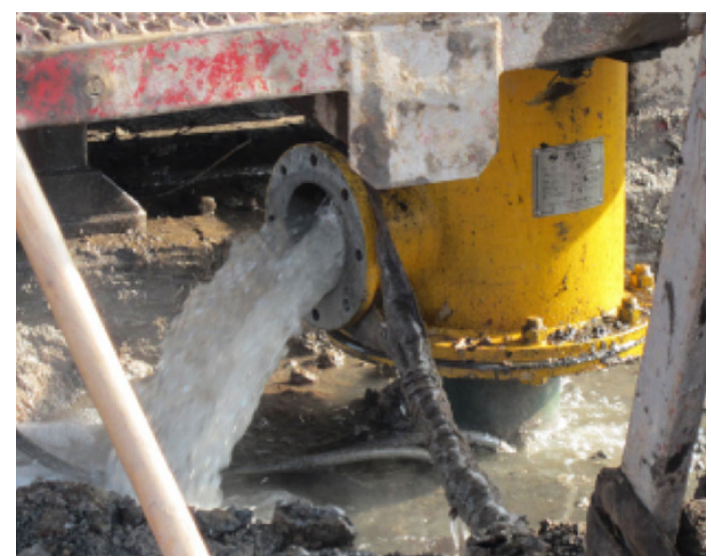

Fig. 8 Underbalanced drilling process with air injection connector

the drilling parameters and the tool system itself should be examined before proceeding to operation. The whole operation is supervised by a manager, who is responsible for the execution of the project. Air injection pipeline should be kept closer to the casing wall while being sent along with the casing. To keep the air pipeline closer to the casing, special stainless steel clamps must be customized for each 1-2 $\mathrm{m}$ of casing length. Special attention should be given during this step and all the engineering practices must be followed as per safety policy.

In the on-site procedure, the air injection connector had been put $400 \mathrm{~m}$ under the hole. The actual injecting pressure value was $3.5 \mathrm{MPa}$. The compressed air volume flow was about $700 \mathrm{~L} / \mathrm{min}$. The underbalanced drilling process with air injection connector had been realized as in the example shown in Fig. 8. The on-site underbalanced drilling was successfully and safely executed with an excellent feedback.

\section{Conclusion}

The technology of underbalanced drilling has been well used for tens of years and is still a good drilling

Table 1 Curve for bottom hole pressure $\Delta P$ in different amounts of gas injected and liquid flow rates under injecting air pressure with $3.5 \mathrm{MPa}$

\begin{tabular}{|c|c|c|c|c|c|c|c|c|}
\hline \multirow[t]{2}{*}{$Q_{\mathrm{w}}$} & \multicolumn{8}{|l|}{$Q_{\mathrm{g}}$} \\
\hline & 20 & 22 & 25 & 27 & 30 & 32 & 35 & 37 \\
\hline 950 & -0.1595 & -0.2000 & -0.2537 & -0.2585 & -0.3278 & -0.3825 & -0.4452 & -0.5155 \\
\hline 900 & -0.1864 & -0.2283 & -0.2834 & -0.3167 & -0.3613 & -0.4011 & -0.4817 & -0.5339 \\
\hline 850 & -0.2200 & -0.2592 & -0.3147 & -0.3511 & -0.3799 & -0.4357 & -0.5005 & -0.5714 \\
\hline 800 & -0.2483 & -0.2908 & -0.3476 & -0.3822 & -0.3990 & -0.4545 & -0.5369 & -0.5905 \\
\hline 750 & -0.2834 & -0.3242 & -0.3802 & -0.4131 & -0.4321 & -0.4893 & -0.5561 & -0.6281 \\
\hline 700 & -0.3154 & -0.3564 & -0.4157 & -0.4483 & -0.4920 & -0.5083 & -0.5927 & -0.6472 \\
\hline
\end{tabular}

$Q_{\mathrm{g}}$ is amount of annular injected air, $\mathrm{m}^{3} / \mathrm{min} ; Q_{\mathrm{w}}$ is drilling liquid flow rates, $\mathrm{L} / \mathrm{s} ; \Delta P$ is bottom pressure value, $\mathrm{MPa}$ 
technology. Using the air injection connector system in underbalanced drilling gives the technology a higher edge. The modification of the underbalanced drilling technology helps to reduce the density of the drilling fluid. Compared to the method of "U-tube" well for air injection, the parasite system with air injection connector is more economically feasible. Quality control plays an important role in the tool design, manufacturing process, experiment, project design, and the on-site procedure, all of which were illustrated in the technology of the underbalanced drilling air injection connector system. As long as these controlling methods and safety rules are followed, the on-site engineering could be executed successfully.

Open Access This article is distributed under the terms of the Creative Commons Attribution License which permits any use, distribution, and reproduction in any medium, provided the original author(s) and the source are credited.

\section{References}

Bennion DB, Lunan B, Saponja J (1998) Underbalanced drilling and completion operations to minimize formation damage-reservoir screening criteria for optimum application. J Can Pet Technol 37(9):36-50

Chen FY, Hu T, Wang J (2010) Study and application of underbalanced drilling and completion technology with nitrogen gas in heavy oil reservoir. J Drill Prod Technol 33(1):11-13

Fried S, Yurkiw F, Girgis M (1996). Gas supply alternatives and corrosion considerations in underbalanced drilling operations. Annual technical meeting, 10-12 June 1996

Hu ZJ, Hou FX, Ma QF (2010) An analysis of the process control technology for drilling fluid continuous circulation system. J China Pet Mach 38:62-65
Li TJ, Yan TN (2005) Problems of application of electromagnetic wave MWD in underbalanced drilling. J Geol Sci Technol Inf 24(S1):37-39

Liu HX, Meng YF (2005) New technology to drill horizontal wells with underbalanced pressure by air injection. J Pet Explor Dev 32(1):100-102

Luo SY, Meng YF, Li Y (2000) A study for mathematical model of form underbalanced drilling in gas reservoir. J Nat Gas Ind 20(5):47-50

Misselbrook J, Wilde G, Falk K (1991). The development and use of a coiled-tubing simulation for horizontal applications. SPE annual technical conference and exhibition, Dallas, Tx, 6-9 Oct 1991, pp 29-41

Omland TH, Saasen A, Taugbøl K (2007) Improved drilling process control through continuous particle and cuttings monitoring. Commence Soc Pet Eng: Digit Energy Conf Exhib SPE 107547:1-7

Oyatomari C, Orellán S, Alvarez R, Bojani R (2002). Application of drilling fluid system based on air microbubbles as an alternative to underbalance drilling technique in reservoir B-6-X.10-Tia Juana, Lake Maracaibo. IADC paper presented at the international association of drilling contractors "Global Leadership for the Drilling Industry" conference in Madrid, Spain, May 2002, pp 1-12

Rolf JL, Kjell KF, Johnny FR (2001) Underbalanced drilling: real time data interpretation and decision support. SPE/IADC Drill Conf 67693:1-9

Rommetveit R, Vefring EH, Wang ZH (2005) A dynamic model for underbalanced drilling with coiled tubing. SPE/LADC Drill Conf 29369:19-30

Xian BA, Zhao QB, Sun P (2009). Air injection connector for underbalanced drilling. China Patent, ZL: 200820123709.0

Zhang Y, Xian BA, Zhao QB, Zhou WD (2009) Optimization of annular gas injection technology in coalbed methane aerated underbalanced drilling. J Pet Explor Dev 36(3):398-401

Zhou YC, Wang GX, Zhai HJ (2003) Application of underbalanced drilling technology in Weishen-5 well of Daqing oilfield. J Acta Pet Sin 24(6):90-97 